
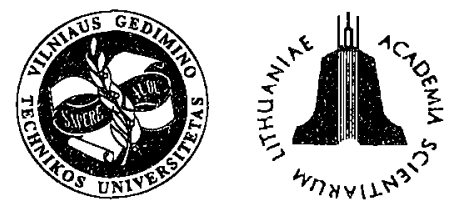

ISSN 1648-4142 TRANSPORT

http:/www.vtu.lt/english/editions

TRANSPORT - 2002, Vol XVII, No 6, 24I-243

\title{
MAKING UP AND RENOVATION OF TRAINS
}

\author{
Gediminas Vaičiūnas ${ }^{1}$, Leonas Povilas Lingaitis ${ }^{2}$ \\ Department of Railway Transport, Vilnius Gediminas Technical University, \\ J. Basanavičiaus g. 28, LT-2009 Vilnius, Lithuania.
}

Received 200206 26; accepted 20021021

\begin{abstract}
Major constituent parts of the railway system are rolling stock and various objects making its infrastructure. Their maintenance is rather expensive, while renovation requires large investments. The researchers all over the world are working hard to make these investments effective. To make a decision in economics its economic effect should be established first. Generally, the latter is expressed as the repay time of investment or the economic effect in the particular period of time specified according to the particular technical requirements. The repay time is usually calculated optimizing the choice of the particular elements (i.e. an.engine, gear - box, transmission, etc.) of the train. The optimization of the selection of the trains would require a comparative analysis of economic effects (expressed in monetary units at the particular time interval) of the alternative solutions available. If the target objects of the investments are well - known, the first approach described in the present paper may be used to determine the repay time of investment thus enabling us to check the effectiveness of a potential investment. If an object for the potential investment should be determined, implying that its major characteristics should be described, the second method based on increasing the economic effect may be applied.
\end{abstract}

Keywords: Traction rolling stocks, train, optimization, economic effect.

\section{Introduction}

Major constituent parts of the railway system are rolling stock and various objects making its infrastructure. Their maintenance is rather expensive, while renovation requires large investments. The researchers all over the world are working hard to make these investments effective [1-3]. They try to improve the maintenance of the rolling stock as well as to search for better power units and transmission elements designing and upgrading the rolling stock. The efforts are also made to reduce the pollution, to save fuel and oil, etc. In our conditions the problem of ageing of the facilities available is very urgent too. In fact, during the last years of soviet regime the problems of renovation and upgrading of rolling stock were not considered. Therefore, a clear - cut concept of rolling stock upgrading has not been formed yet. This is done occasionally, based on the intuition of the experienced staff of enterprises. In 1999 a program of renovation of the locomotive 2M62 was developed and the efforts are being made now to reduce the wearing of wheel - set tyres of the locomotive CME 3 and 2M62 providing an effective lubrication system. Wagons of the diesel locomotive D1 have been updated replacing old - fashioned speed gear - boxes. All these measures resulted in considerable savings. However, the experience has shown

\footnotetext{
'E-mail: vaic@ti.vtu.lt

2E-mail: leonas1@ti.vtu.lt
}

that without a clear - cut programme it is hardly possible to expect much of rolling stock renovation. A conclusion can be made that simple, clear and reliable algorithm determining the purpose of the locomotive (and their stock) renovation should be developed in any particular case.

\section{Optimization of a Mathematical Model}

To make a decision in economics its economic effect should be established first. Generally, the latter is expressed as the repay time of investment or the economic effect in the particular period of time specified according to the particular technical requirements. The repay time is usually calculated optimizing the choice of the particular elements (i.e. an engine, gear - box, transmission, etc.) of the train. The optimization of the selection of the trains would require a comparative analysis of economic effects (expressed in monetary units at the particular time interval) of the alternative solutions available. A mathematical model to be used analyzing the ways of upgrading the locomotives $2 \mathrm{M} 62$ and forecasting the time of the repay of investments has been developed. It may be expressed in a most general way as follows:

$$
L_{a t s}=\frac{I}{M-M_{m}},
$$

here, $L_{\text {als }}$ - repay time, years; 
$I$ - costs of upgrading the particular element, EU;

$M_{m}$ - operational expenses of an upgraded element per year, EU per year;

$M$ - operational expenses of an old (not - upgraded) element per year, EU per year.

In the case of the replacement of the existing engines in the locomotives $2 \mathrm{M} 62$ by the western models the expenses $I$ consist of the costs of purchasing and installing a new engine in the locomotive. Yearly operational expenses $M_{m}$ and $\mathrm{M}$ are yearly expenses on fuels and oils for the locomotive with a western - type engine or for one having the engine 14D40. The following equation describing the dynamics of expenses has been derived:

$$
\left\{\begin{array}{l}
I_{m}=I_{m}^{m}+I_{m t} \times t \\
I_{14 D 40}=I_{14 D 40 t} \times t
\end{array},\right.
$$

here, $I_{m}$ and $I_{14 D 40}$ - expenses related to a modernized locomotive (with a western - type engine) and expenses related to the locomotives with the engine 14D40, EU;

$I_{m}^{m}$ - expenses related to purchasing and installation of a western - type engine in the locomotive, EU;

$I_{m}$ and $I_{14 D 40 m}$ - operational expenses (of the locomotives with a western type engine and the engine 14D40, respectively) in the particular period of time, EU per year; $t$ - time period, years.

Graphical representation of the system is given in Fig 1.

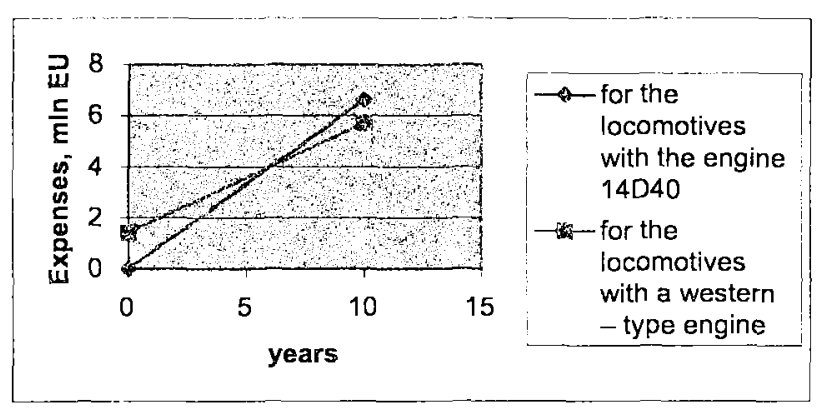

Fig 1. Graphs of equations expressing variation of expenses

Both graphical and analytical solutions show that the replacement of the engine $14 \mathrm{D} 40$ by a western model could repay in $5-6$ years. It means that from economical perspective this type of renovation may be effective when the specified life of the locomotives is still much longer than $5-6$ years. In this way it is possible to determine the repay time of future investments. However, the objects of investment should be well - known: it should be clear what should be purchased and what should be installed and reconstructed. In case when an object of investment is to be chosen the repay time of every potential investment may be determined which would allow us to choose the investment capable of repaying in the shortest time. This type of optimization enables us to determine the investment which has the shortest repay time, not showing, however, its economic effect expressed in money. When the latter is not known it is hardly possible to determine the real value of the particular investment with respect to others. Therefore, sometimes the optimization when the efficiency function is an economic effect expressed in monetary units is more useful. The choice of traction rolling stocks is the case in point [4]. General economic effect may be calculated in this way:

$$
E=E_{a}-E_{e}
$$

$E_{a}$ - income, Lt; $E_{e}$ - operational expenses, EU.

Determining the dependence of fuel expenditure and time of travel on the locomotive power and power per unit mass of the train we may obtain the relationship between the economic effect and the locomotive power and power per unit mass of the train:

$$
\begin{aligned}
& E=\frac{N}{N_{t}} \cdot p_{a}-\left((A \cdot N+B) \cdot N_{t}^{x} \cdot k_{d}+\right. \\
& \left.C \cdot N^{y}{ }_{t} \cdot k_{l}\right) \cdot L_{2}
\end{aligned}
$$

here $A, B, x$ - dependence coefficients of fuel expenditure; c, y-dependence coefficients of carriage time; $L-$ track length, $\mathrm{km} ; N$ - locomotive power, $\mathrm{kW} ; N_{t}-$ locomotive power per unit mass of the train, $\mathrm{kW} / \mathrm{t} ; k_{d}-$ fuel expenses, EU/kg; $k_{j}$ - relative carriage time, EU/min; $p_{a}$ - income for a gross ton of cargo carried, EU/ton.

Having applied the above formula to the road Kena - Klaipeda of the length $L=445 \mathrm{~km}$, we obtained the relationship:

$$
\begin{aligned}
& E=\frac{N}{N_{t}} \cdot p_{a}-\left((0,0295 \cdot N+0,946) \cdot N_{t}^{-0,333} \cdot k_{d}+\right. \\
& \left.22,56 \cdot N^{0,31} \cdot k_{l}\right) \cdot 445 .
\end{aligned}
$$

The above dependence is graphically shown in Fig 2. The graph is based on statistical economic data (i.e. costs of carriage, fuel expenses, time of carriage, etc.). These characteristics are changing in time and their change may quantitatively alter the economic effect. However, the tendency of qualitative changes will stay the same. The reliability of the described and other relationships (given below) is $95 \%$, while their probability is $\pm 2 \%$.

As we can see graphically expressed mathematical model in Fig 2 has no extremums. Therefore, the optimal

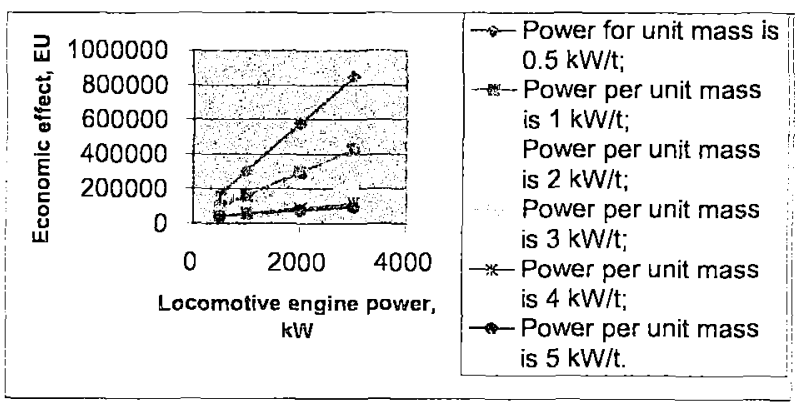

Fig 2. The economic effect of one conditional haul depending on the engine power and the engine power per unit mass 
Table 1. The dependence of optimal locomotive power on freight turnover

\begin{tabular}{|c|c|c|c|c|c|c|c|c|c|c|c|c|}
\hline $\mathrm{A}, 10^{3} \mathrm{t}$ & 10 & 15 & 20 & 25 & 30 & 35 & 40 & 45 & 50 & 55 & 60 & 65 \\
\hline $\mathrm{N}, \mathrm{kW}$ & 673 & 927 & 1163 & 1301 & 1387 & 1808 & 2008 & 2240 & 5253 & 10091 & 18313 & 31687 \\
\hline
\end{tabular}

A - expected tumover, tons thous. per day (24 hours);

$\mathrm{N}$ - recommended locomotive power, $\mathrm{kW}$.

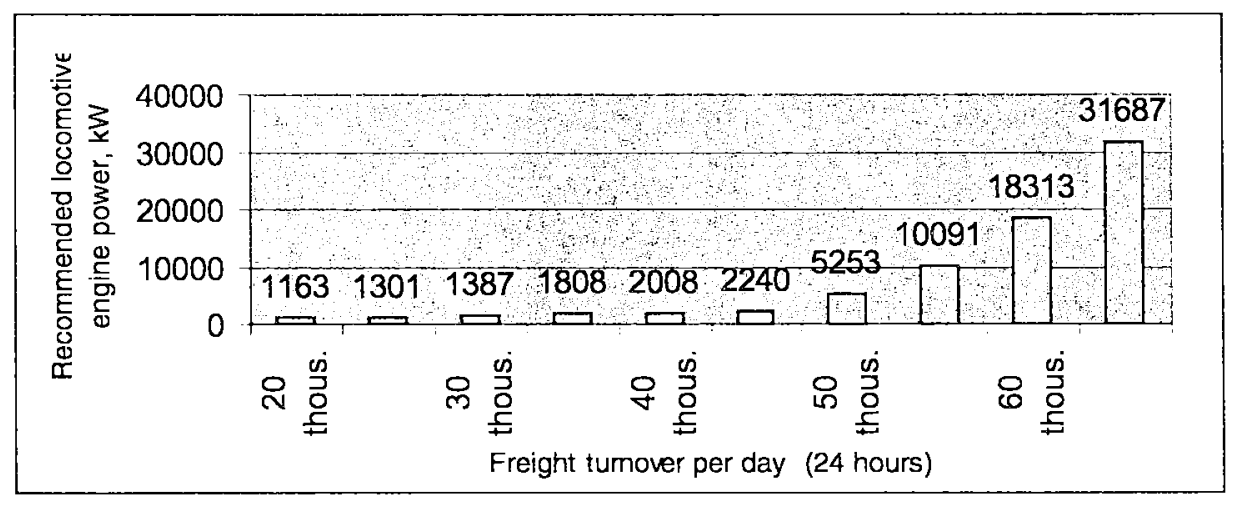

Fig 3. Optimal locomotive engine power depending on calculated difference of streams of cargo

points should be chosen based on constraints. Since power is needed for overcoming the rolling resistance, there are the constraints on power per unit mass. In addition, a constraint on the length of the train is imposed. The given fixed locomotive and train length and the power per unit mass are restricted as well. The restriction is also determined by axle loading (because the higher the axle loading, the larger mass per unit track length). Both constraints can be described by the respective equations:

$$
\left\{\begin{array}{l}
N_{t}=8,783 \cdot N^{-0,3134} \\
N=2731,5 \cdot N_{t}
\end{array}\right.
$$

The analysis of the equation system (6) yields the relationship between the optimal locomotive power and freight turnover [4]. It is given in Table 1, while its graphical representation can be found in Fig 3.

In Fig 3 we can see that freight tumover reaches up to 45,000 tons per day, while the recommended locomotive power is about $2,500 \mathrm{~kW}$. It is not possible to increase the weight of the cargo because of the inefficient length of approach and departure lines of the track Kena - Klaipeda. Therefore, the increase of the freight turnover rate up to 45, 000 tons per day may be achieved only increasing the speed of the trains. However, the locomotive power should be increased for this purpose too.

\section{Conclusions}

1. Planning the investments in the railway rolling stock and optimizing the selection of trains and their units the optimization methods should be chosen with account of the nature of the expected investment.
2. If the target objects of the investments are well known, the first approach described in the present paper may be used to determine the repay time of investment thus enabling us to check the effectiveness of a potential investment.

3. If an object for the potential investment should be determined implying that its major characteristics should be described, the second method based on increasing the economic effect may be applied.

\section{References}

1. Lingaitis L. P.; Vaičiūnas G. An optimization model of traction rolling stock operation. Maintenance and reliability, No 3(15)/2002. Polskie Naukowo-Techniczne Towarzystwo Eksplatacyjne Warsawa, ISSN 1507-2711, p 26-30.

2. Tsai W. F. Finite Analytic Model for flow and Transport Unsaturated Zone. Journal of engineering mechanics, May 2000, No 5, p 470-498, ISSN 0733-9399.

3. O'Brien W. J.; Fisher M. A. Importance of Capitaly Contrains to Cost and Schedule. Journal of construction management. Sept./oct. 2000, No 5, p 366-373, ISSN 0739-9364.

4. Vaičiūnas G.; Lingaitis L. P. The influence of asymmetry of streams of loads on the choice of traction rolling-stocks. Transport Engineering (Transportas), Vol XVI, No 2, Vilnius: Technika, 2001, p 77-81 (in Lithuanian), ISSN 1392-1533. 